\title{
Descending Necrotizing Mediastinitis: Review of the Literature and Controversies in Management
}

\author{
Christophoros N. Foroulis ${ }^{* 1}$ and Maria N. Sileli ${ }^{2}$ \\ ${ }^{I}$ Aristotle University Medical School, AHEPA University Hospital, Department of Thoracic and Cardiovascular \\ Surgery, 54636 Thessaloniki, Greece \\ ${ }^{2}$ General Hospital Papanikolaou, $2^{\text {nd }}$ Department of Intensive Care Medicine, 57010 Thessaloniki, Greece
}

\begin{abstract}
Any deep cervical infection has to be aggressively treated and CT scan of the chest should be performed to exclude the possibility of downward spread of the infection within the mediastinum. Early recognition of DNM is problematic because of its rarity and the non-specific symptoms in its early phase. DNM can rapidly progress to involve the entire mediastinum.

Aggressive surgery upon diagnosis has to be performed, usually through a combination of cervicomediastinal and thoracic approach. Cervicomediastinal drainage alone for DNM not extending below the carina level or combined with subxiphoid drainage or anterior mediastinotomies is associated with higher mortality rates. Thoracotomy on the most involved side or bilateral thoracotomies give the best exposure for adequate mediastinal drainage. Median sternotomy or VATS procedures can be performed if one-lung ventilation can be tolerated by the patient. Pleural and pericardial cavities and all mediastinal spaces should be properly drained. Repeat CT scan of the neck and chest should be performed in all patients 48-72 hours after drainage of the infection or even earlier in case of further deterioration of the patient or persistent sepsis.

Mortality rate in recent series ranges between $10 \%$ and $30 \%$. The development of purulent pericarditis and/or failure of more than two organs before mediastinal drainage are associated with higher risk of fatal outcome. Prolonged ICU and hospital stays are the rule, while re-intervention rate for persistent sepsis exceeds $30 \%$. The re-intervention rate is higher after mediastinal drainage performed through approaches which offer limited exposure to the whole mediastinum.
\end{abstract}

Keywords: Mediastinum, mediastinal infections, mediastinitis, descending necrotizing mediastinitis.

\section{INTRODUCTION}

Descending necrotizing mediastinitis (DNM) is an uncommon, serious and fulminant form of mediastinitis which is the result of spread of a severe cervical infection down to the mediastinum $[1,2]$. In the present mini review we make a synopsis of the available data, especially the recently published, on diagnosis, classification and treatment of DNM and we compare the results of those data with the personal experience of the $1^{\text {st }}$ author which includes 7 cases of DNM seen during a 15-year period of involvement in thoracic surgery. Useful algorithms to plan treatment are arranged and all controversies concerning surgical treatment of DNM are discussed.

\section{BACKGROUND AND PATHOPHYSIOLOGY}

The responsible for the generation of DNM cervical infection descends to the mediastinum through the deep and superficial cervical fascial planes that are continuous with those of the mediastinum. The infection descends to the mediastinum through the pretracheal, paraesophageal, prevertebral and retropharyngeal spaces and along the carotid

*Address correspondence to this author at the AHEPA University Hospital, 1 Stilponos Kiriakidi Street, 54636 Thessaloniki, Greece; Tel: 0030-2310994705; Fax: 0030-2310-994871; E-mail: cforoulis@otenet.gr, foroulis@med.auth.gr sheaths. The retropharyngeal space that extends from the skull base to the mediastinum has important clinical significance for the spread of odontogenic infections within the posterior mediastinum and pleural space and it is called the "danger" space. Gravity and the negative intrathoracic pressure facilitate the spread of cervical infections down to the mediastinum through the above mentioned cervicomediastinal fascial planes [1-4].

DNM is a relatively rare condition and it is accompanied by high mortality rates, especially if diagnosis and treatment are delayed for more than 24 hours after the onset of symptoms $[1,2]$. The rarity of the disease and the non-specific symptoms in the early phase of mediastinal involvement are responsible for the late recognition in most cases [1]. The available information concerning diagnosis and treatment come from relatively small case series, and consequently no standard form of treatment exists [4, 7-12]. The disease predominantly affects young men [1, 2, 4-12].

The most common causes of DNM are odontogenic infections, peritonsilar and retropharyngeal abscesses [1-3]. Traumatic pharyngeal perforations by foreign bodies (fish or chicken bones), suicide attempts, iatrogenic pharyngeal perforations and Ludwig angina are other, rare causes of DNM $[1,2]$. DNM is in most cases a mixed infection from aerobic and anaerobic species, although aerobic $\beta$-hemolytic streptococcus may be the only responsible microorganism. In mixed aerobic and anaerobic infections, the symbiosis 
between one or more species of microorganisms results in a synergistic necrotizing cellulitis and multiple small vessel thrombosis that becomes clinically evident within 24-72 hours after the onset of a deep cervical infection or following an odontogenic procedure $[1,2]$. The commonest microorganisms found in DNM are aerobic and anaerobic streptococci, Fusobacterium, bacteroides species, Staphylococci, Haemophilus species, clostridium perfringens, Esherichia coli and pseudomonas aeruginosa [1-12].

\section{DIAGNOSIS}

Early recognition of DNM is very important, before spread of the infection to the lower part of mediastinum, event that seriously affects the general condition of the patient and leads to the development of multiple organ dysfunction (MOD) and failure (MOF). Usually DNM is initially presented with signs of a deep cervical infection, such as swelling, erythema, tenderness and crepitation (because of cervical subcutaneous emphysema) in the neck $[1,2,7,8]$. The cervical infection may rapidly progress to involve the mediastinum, even after prompt drainage of the deep cervical space and administration of broad-spectrum antimicrobials. Dentists and otolaryngologists should be well informed and aware about this rare condition and should have a high index of suspicion when deal with any deep cervical infection for the possibility to extend downwards to the mediastinum. Mediastinal infection, if unrecognized in its early stage, will rapidly progress to involve the entire mediastinum leading to sepsis and MOF.

Symptoms and signs of mediastinal involvement include substernal and pleuritic pain, dysphagia, dyspnea, signs of pleural and/or pericardial effusion and septic shock $[1,2,7$, 8]. The diagnosis of mediastinal involvement is often delayed and in many patients the diagnosis will be made after the deterioration of their general condition because of sepsis. In the personal experience of the $1^{\text {st }}$ author, most patients are seen by the thoracic surgeon after the establishment of MOD or MOF (Table 1).

The diagnostic criteria to establish the diagnosis of DNM were reported by Estrera et al. in 1983 and still remain valid until today [4]. The Estrera's criteria are the following:

1. Clinical manifestations of severe infection

2. Demonstration of characteristic radiographic features such as mediastinal widening, mediastinal emphysema, mediastinal fluid collection with bubbles or abscesses with air fluid level

3. Documentation of necrotizing mediastinal infection at operation or post-morten examination or both

4. Establishment of the relationship of oropharyngeal or cervical infection with the development of the necrotizing mediastinal process

\section{RADIOLOGIC FINDINGS}

The main findings in plain chest radiography will make the suspicion of DNM together with the clinical signs and symptoms of severe infection and with the presence of a cervical or oropharyngeal infection. The radiologic findings in plain chest radiography are the following:

- $\quad$ widening of the mediastinum and mediastinal emphysema

- $\quad$ air-fluid levels within the mediastinal shadow

- $\quad$ anterior displacement of the tracheal air column by a prevertebral soft tissue opacity

- $\quad$ enlargement of the cardiac silhouette and loss of the normal cervical spine lordosis

- unilateral or bilateral pleural effusion [5]

CT scan of the chest and neck is an important examination in any patient who is treated for a deep cervival infection in order to early recognize the presence of mediastinal involvement. [4, 6] CT scan shows soft tissue infiltration with loss of the normal appearance of mediastinal fat (increased density), mediastinal emphysema and mediastinal fluid collections with or without air bubbles (Figs. 1, 2 and 3). Pleural and pericardial effusions can also be demonstrated [5, 6] (Fig. 4).

CT scan of the chest gives important information concerning the extent of mediastinal involvement. CT scan will delineate if the infectious mediastinal process extends or not below the carina level, an information that is considered crucial by many authors before to plan surgical treatment [1, 2, 4, 6, 11, 13] (Fig. 5). The involvement of one or more mediastinal compartments is also essential for planning surgical drainage. DNM is classified by Hasegawa et al. in 3

Table 1. Personal Experience of the First Author with 7 Cases of DNM: The Mortality Rate is 23.5\% by a Combination of Cervicomediastinal and Transthoracic Drainage

\begin{tabular}{|c|c|c|c|c|c|}
\hline Source of Infection & Age & Drainage Procedures & $\begin{array}{c}\text { Purulent } \\
\text { Pericarditis }\end{array}$ & $\begin{array}{c}\text { Organ Dysfunction } \\
\text { Before Surgery }\end{array}$ & Outcome \\
\hline odontogenic & 31 & Cervicomediastinal $+(\mathrm{R})$ thoracotomy $+(\mathrm{L})$ chest tube & No & 1 & survival \\
\hline odontogenic & 18 & Cervicomediastinal +bilateral thoracotomy & Yes & 3 & death \\
\hline Pharyngeal perforation & 21 & Cervicomediastinal $+(\mathrm{R})$ thoracotomy & No & 2 & survival \\
\hline Pharyngeal perforation & 42 & Cervicomediastinal + bilateral thoracotomy & No & 2 & survival \\
\hline odontogenic & 39 & Cervicomediastinal + bilateral thoracotomy & Yes & 3 & death \\
\hline
\end{tabular}




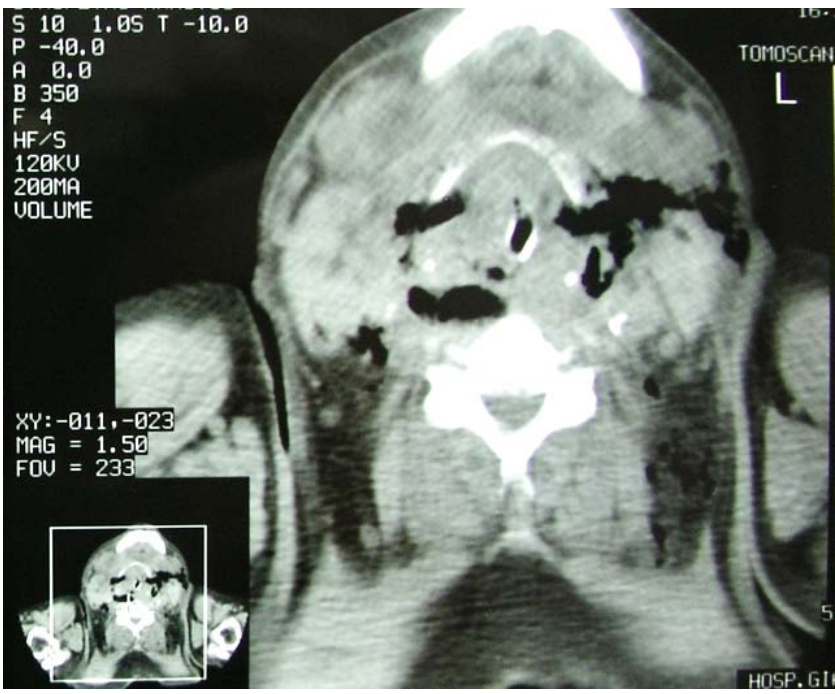

Fig. (1). DNM after odontogenic infection: Cervical emphysema and increased density of the cervical fat.

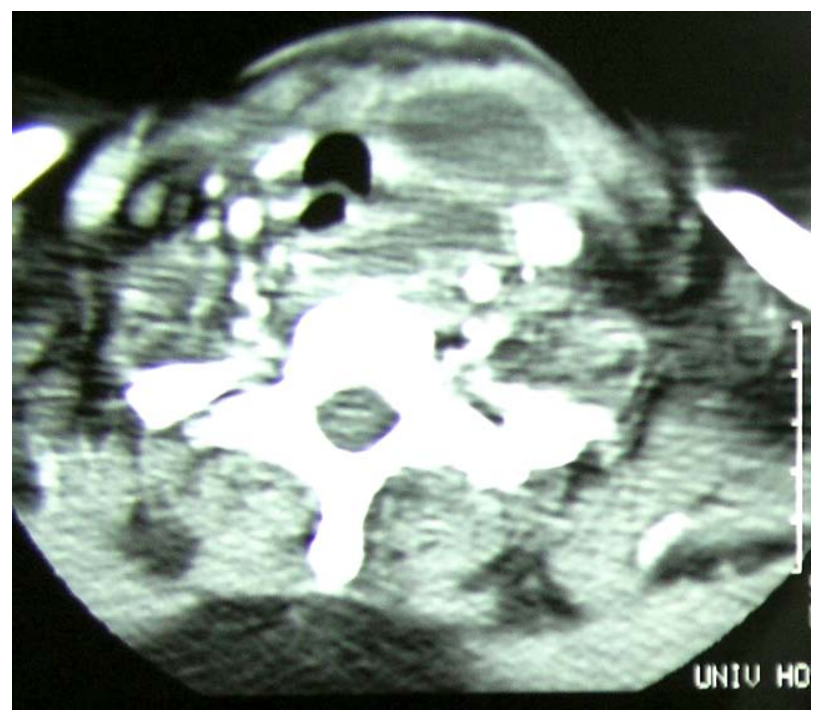

Fig. (2). DNM after odontogenic infection: Cervical abscess and loss of the normal appearance of cervical fat.

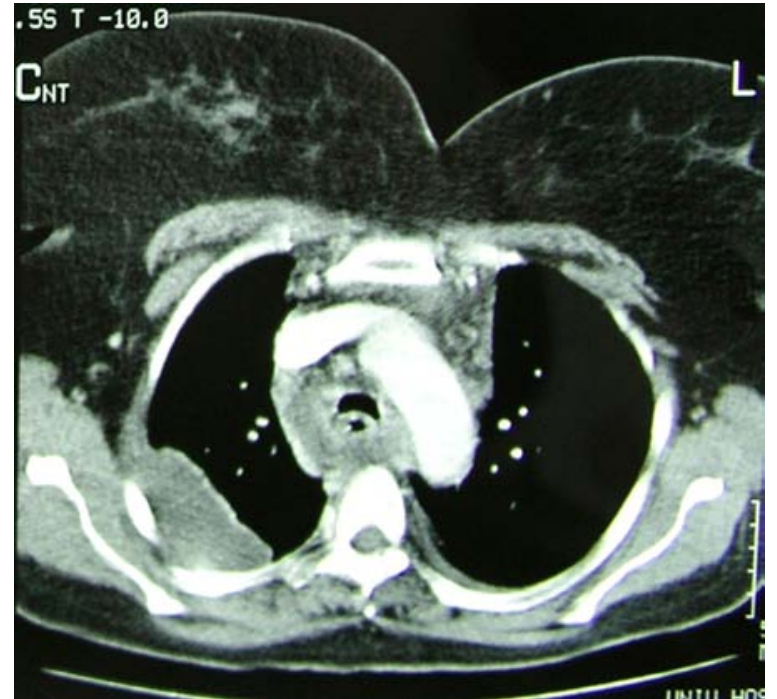

Fig. (3). DNM: enlargement of the mediastinum, increased density of the mediastinal fat and mediastinal emphysema.

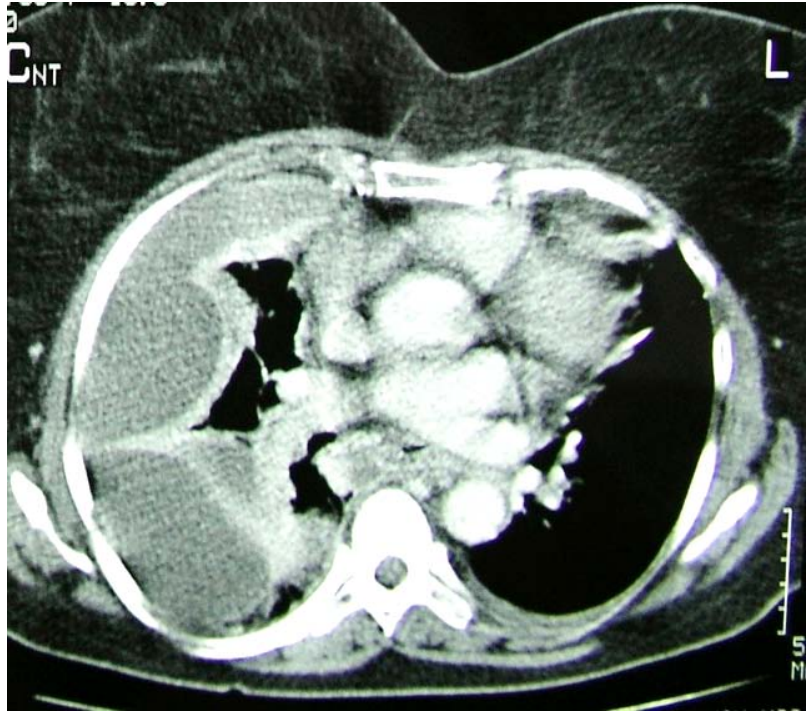

Fig. (4). DNM: Multiloculated right pleural effusions (empyema) and loss of the normal appearance of pericardial fat.

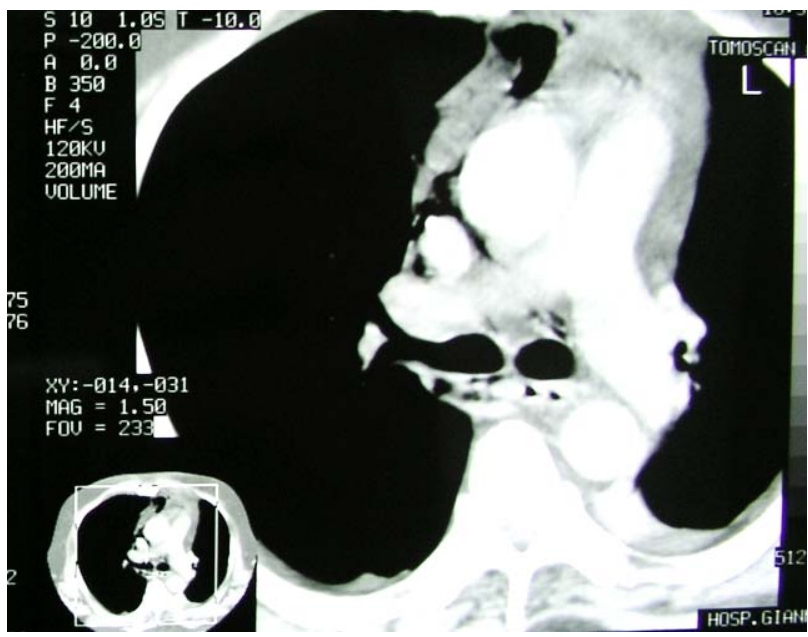

Fig. (5). DNM extending below the carina level: Mediastinal emphysema and increased density of the mediastinal fat below the tracheal bifurcation. Diffusion of the infection on both sides of the mediastinum.

types according to its diffusion within the mediastinum [13] (Figs. 6 and 7). Classification is based on CT findings and the 3 proposed types are the following:

Type I: the infection is localized to the upper mediastinum and above the tracheal bifurcation

Type IIA: the infection extends to the lower anterior mediastinum

Type IIB: the infection extends to the lower anterior and posterior mediastinum

CT scan of the chest and neck is also an important examination to monitor the adequacy of mediastinal drainage after surgery and for the decision-making to re-operate if the infection persists or relapses within the mediastinum $[9,10$, 14].

The suspicion is the key for the diagnosis of DNM. Early diagnosis and treatment is further the key for early surgical intervention that gives the best chance for a favorable 
outcome. Early consultation from a thoracic surgeon offers to the patient the aggressive surgical treatment that is necessary for this aggressive disease with lethal outcome in case of delayed or inappropriate treatment $[7,14]$.

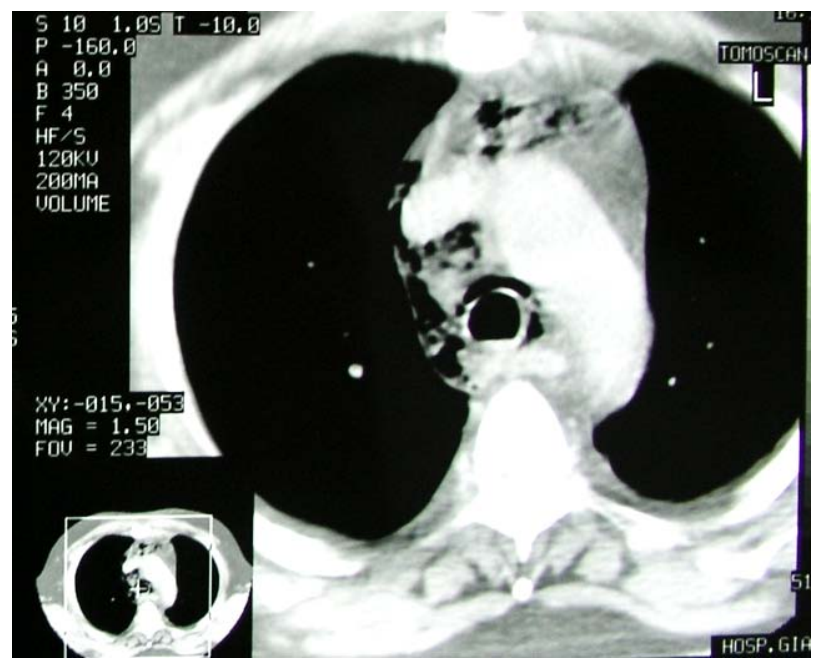

Fig. (6). DNM involving the anterior, middle and posterior mediastinum: Mediastinal emphysema and loss of the normal appearance of mediastinal fat.

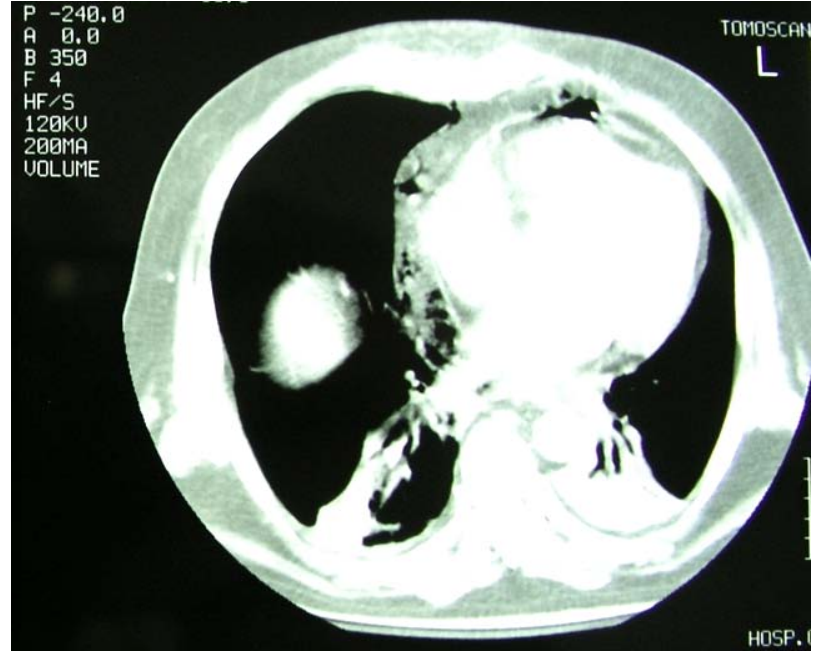

Fig. (7). DNM: Increased density of the pericardial fat on both sides and emphysema within the pericardial fat. Atelectasis of the left lower lobe and loculated pleural effusion within the interlobar fissure of the right lung.

\section{TREATMENT}

Aggressive cervical and mediastinal debridement and drainage, effective pleural and pericardial drainage, administration of broad spectrum antibiotics, covering both aerobes and anaerobes, and support of the vital organs in the ICU are the four important parameters for the treatment of DNM.

Many different approaches are reported for mediastinal drainage in DNM, according to the level of mediastinitis diffusion. The level of the carina is considered by some authors to be the lower border of the infectious spread where a transcervical approach could be effective to drain the mediastinal infection $[1,2,4,11,13,15]$. If the infection spreads below this level, the thorax has to be opened to radically drain the infection. In my experience including seven cases of DNM, I believe that a transcervical approach never gives to the surgeon the full exposure that is necessary to properly drain the mediastinum. In addition, the process diffuses rapidly within the mediastinum in fulminant forms of DNM and surgical findings are quite different from that described and seen in CT scan performed just few hours before surgery. The deterioration of vital organs is another guide to plan surgical treatment. In the presence of MOD MOF, aggressive surgery and aggressive mediastinal debridement and drainage has to be offered at $1^{\text {st }}$ operation.

The different surgical approaches which are reported in the literature to drain the mediastinum in DNM are the following:

- Transcervical drainage plus thoracotomy [16]

- Transcervical drainage plus median sternotomy $[17,18]$

- Transcervical drainage plus VATS [19, 20]

- Transcervical drainage plus bilateral thoracotomy [6, 10] (Table 1)

- Transcervical drainage plus Clamshell incision [21]

- Transcervical drainage plus bilateral or unilateral anterior mediastinotomy $[1,7,11]$

- Trancervical drainage plus subxiphoid drainage $[1,9,11]$

- Transcervical drainage alone only for type I DNM [1, 2, 4, $11,13,15]$

Despite the various surgical approaches proposed and used for surgical drainage in DNM, the optimal approach still remains controversial. Limited surgical exposure to the mediastinum that is provided by the combination of transcervical drainage combined with subxiphoid drainage or unilateral / bilateral anterior mediastinotomies or by transcervical drainage alone (only for type I DNM) have all the obvious disantavantage of possible non-adequate drainage of the mediastinum. In the meta-analysis published by Corsten et al. in 1997, the authors conclude that "the mediastinum cannot be adequately drained by a limited surgical approach through subxiphoid or anterior mediastinotomy" and that "all the survivors had the mediastinal sepsis best controlled by formal thoracotomy." The difference in survival between patients operated with limited surgical approaches versus formal thoracotomies was significant in their meta-analysis (53\% versus $81 \%$ ) [8].

Failure to achieve complete mediastinal drainage and debridement is associated with increased risk of lethal outcome. Routine chest and neck CT scan 48 to 72 hours after the initial drainage procedure or in case of persistent sepsis after an initial drainage procedure confirms the adequacy of mediastinal sepsis control [6, 10, 22]. A useful algorithm for the treatment and monitoring of the treatment results in DNM was proposed by Freeman et al. and is presented in Fig. (8) [10].

In the opinion of the $1^{\text {st }}$ author, median sternotomy and Clamshell incisions have the obvious disantvantage of sternal split in an infectious environment where the possibility of the development of deep sternal wound infection is 
Deep cervical neck infection - suspected DNM

Multidisciplinary surgical evaluation

Broad spectrum antibiotics

$\downarrow$

Cervical \& thoracic CT scan

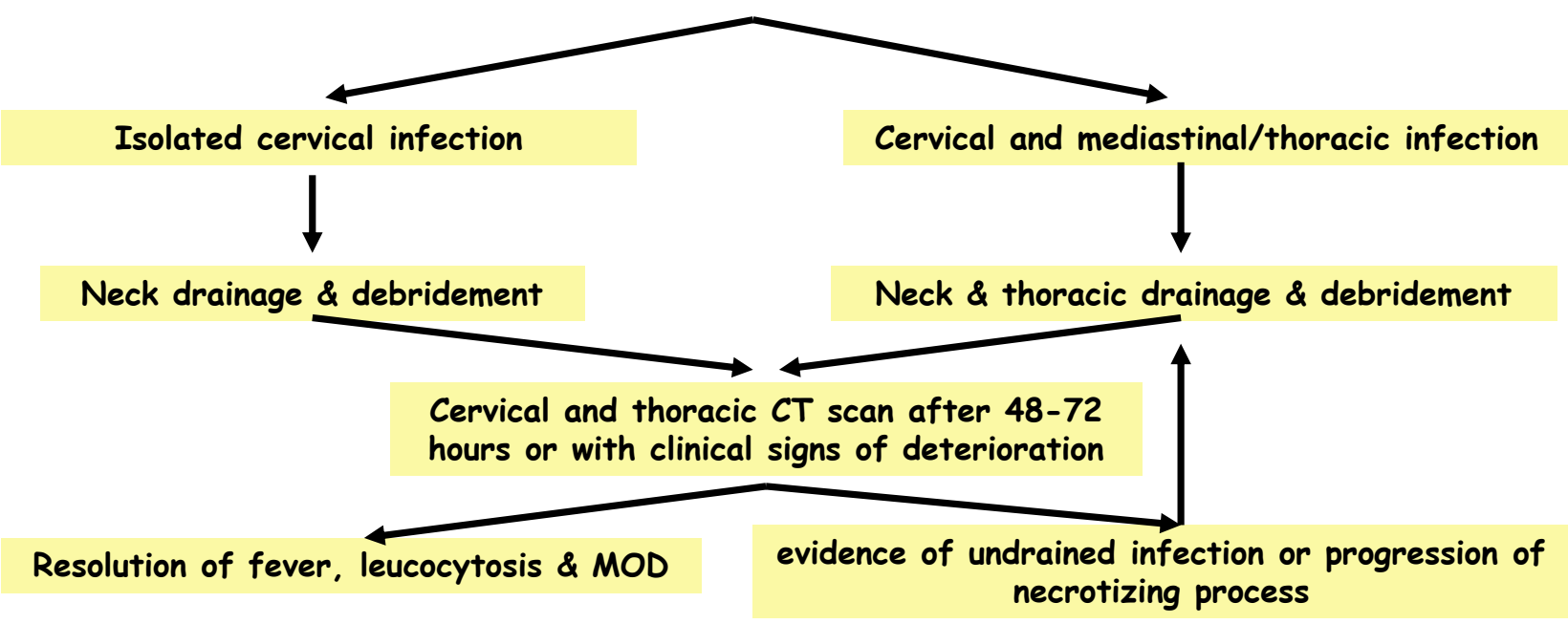

Algorithm from Freeman et al, J Thorac Cardiovasc Surg 2000

Fig. (8). The proposed by Freeman et al. algorithm for the treatment of DNM [10].

considered to be high. Indeed mediastinal debridement via median sternotomy can be accomplished by the application of a vacuum-assisted closure device according to Gorlitzer et al. that helps to avoid deep sternal wound infection [23]. In addition the access to the posterior mediastinum, where DNM frequently spreads, is limited through sternotomies. We should keep in mind that one-lung ventilation is not possible in most patients with DNM because of the associated respiratory failure. Sufficient oxygenation of the patient during the procedure can only be achieved with the inspiration of pure oxygen and high levels of PEEP while serious desaturation occurs shortly after initiation of onelung ventilation. These circumstances preclude in most instances one-lung ventilation which is a necessary parameter to reach the posterior mediastinum through sternotomy and especially to perform a VATS procedure. Respiratory failure was always the case in the 7 cases reported by the 1 st author (Table 1) which made one-lung ventilation impossible except for very short periods of time. Unilateral or bilateral VATS mediastinal drainage can be an alternative way to thoracotomy for mediastinal drainage in cases where onelung ventilation can be tolerated by the patient $[24,25]$.

Unilateral thoracotomy in the most involved side or simultaneous bilateral thoracotomies (in case of diffusion of the infection in both sides according to CT findings) in addition to cervicomediastinal drainage offer the best chance to achieve adequate cervical, mediastinal, pleural and pericar- dial drainage (Table 1). In the opinion of the author the operation should always start with cervical drainage in the affected side or in both sides through an extended collar-cuff incision or bilateral parasternocledomastoid incisions. Finger exploration and drainage of the pretracheal and prevertebral space should be performed at this stage. Multiple penrose drains can be left in place before closure of the cervical incicion/incisions within the deep cervical spaces and in the pretracheal space. The skin incision can be simply reapproximated with interrupted sutures or left open.

During a right thoracotomy the mediastinal pleura should be widely opened from the diaphragm to the azygous vein along the esophagus and the prevertebral space has to be explored and drained by blunt (finger) dissection. The space between the esophagus and the root of the lung should also be bluntly dissected and drained. The mediastinal pleura should also incised from the azygous vein to the thoracic inlet, anteriorly and posteriorly to the trachea. Another incision should be done anteriorly to the superior vena cava and the anterosuperior mediastinum should be drained by blunt dissection. Through this last incision the surgeon can rich the opposite side. The pericardium should also be incised anteriorly to the phrenic nerve. This way all mediastinal spaces are bluntly dissected and any mediastinal collection of fluid or mediastinal abscess will be drained. Bleeding is limited because of the thrombosis of small mediastinal vessels. 
Table 2. DNM: Mortality Rates, Length of ICU and Hospital Stays and Reintervention Rates Reported in the Larger Published Series from 1997 to 2009

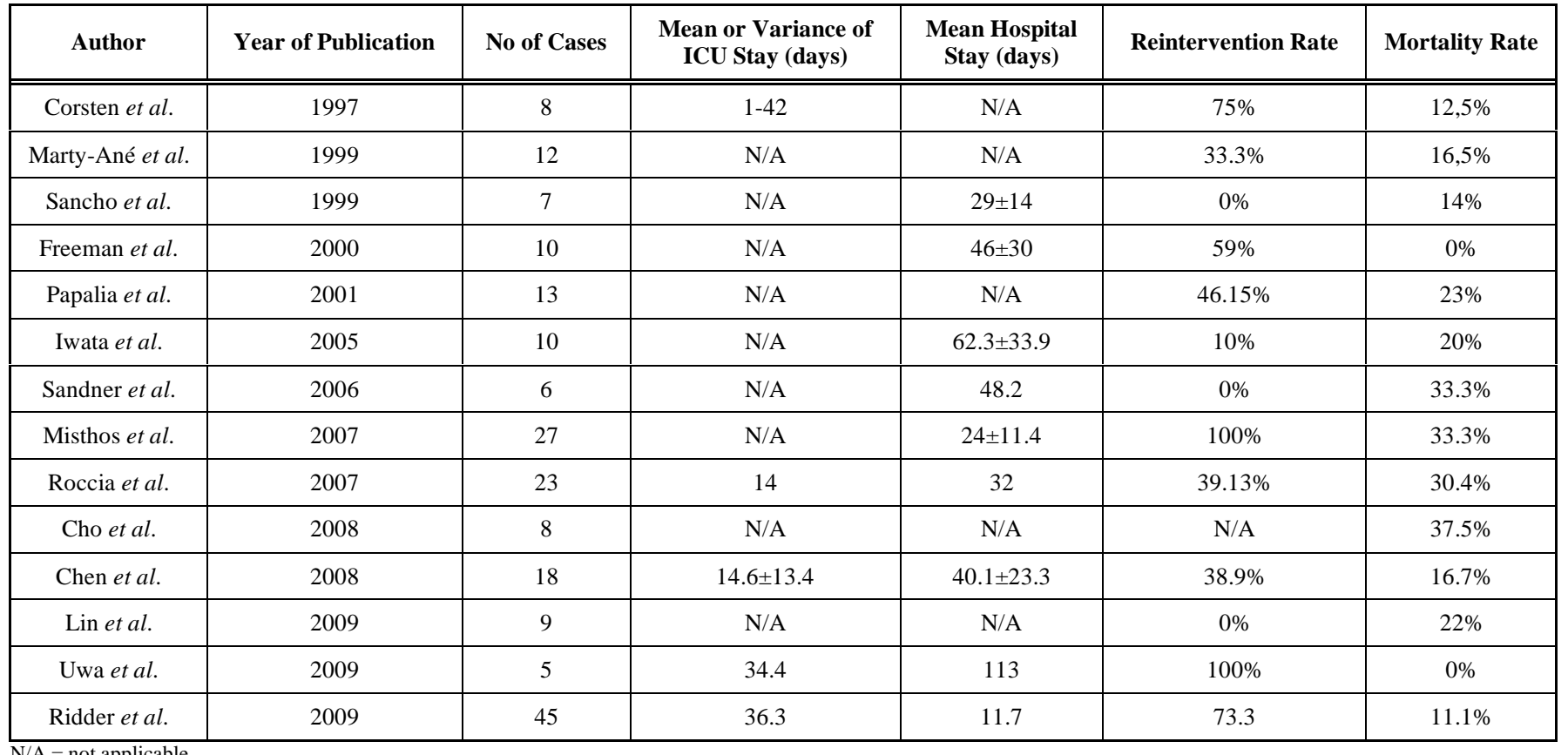

N/A = not applicable.

During a left thoracotomy, the mediastinal pleura should be incised from the diaphragm to the aortic arch along the esophagus. The spaces between the esophagus and descending aorta and between esophagus and the root of the lung should be explored and drained. Incisions in the mediastinal pleura should also be performed between the left carotid and left subclavian arteries from the aortic arch to the thoracic outlet. The pericardial fat should also be bluntly dissected and drained and a pericardial window has also to be made anteriorly to the phrenic nerve for drainage of the pericardial cavity. Of importance is to explore and to drain the substernal space.

Two large chest tubes should be left in place before thoracotomy closure. The skin can be re-approximated by interrupted skin sutures or left open.

Detection of diffusion of DNM within the entire mediastinum in preoperative CT scan will obviate the need for simultaneous bilateral thoracotomies in addition to cervicomediastinal drainage through the neck (Fig. 5). Bilateral thoracotomy in 3 out of 7 cases and right thoracotomy with or without chest tube drainage of the left pleural cavity in the rest 4 cases were chosen as the appropriate access for drainage of DNM in the series of 7 cases presented in Table 1.

\section{OUTCOME}

Mortality rates still remain high, and ranges between $12.5 \%$ and $37.5 \%$ in most of the recently published series. The main cause of death is MOF (Table 2). Cervicomediastinal drainage of DNM is associated with higher mortality rates than the combination of transcervical and transthoracic drainage $(47 \%$ vs. $19 \%)$ in the meta-analysis published by Corsten et al. [6]. The development of purulent pericarditis and/or failure of more than 2 organs before surgery, probably as the result of delayed diagnosis, are connected with high probability of death in the series of 7 patients that is presented in Table 1. Support of the failed organs in the ICU is of paramount importance for a good outcome of any patient who undergoes mediastinal drainage for DNM [26-31]. Prolonged ICU and hospital stays are the rule for patients treated for DNM in most of published series (Table 2) and in the personal experience of the authors [2631]. Need for a second or even more surgical interventions is reported to be high $(33 \%-100 \%)$ in most of published series (Table 2) and especially after a $1^{\text {st }}$ attempt to drain the mediastinum through the neck [26-31].

\section{REFERENCES}

[1] Liptay MJ, Fry WA, Shields TW. Acute and chronic mediastinal infections. In: Shields TW, LoCicero J, Ponn RB, Eds. Shields General Thoracic Surgery. Philadelphia: Lippincott Williams and Willkins 2000; 2093-104.

[2] Van Natta TL, Iannettoni MD. Acute necrotizing medistinitis. In: Patterson AG, Cooper JD, Deslauriers J, Lerut AEMR, Luketich JD, Rice TW, Eds. Pearson's Thoracic and Esophageal Surgery. Philadelphia: Churchill Livingstone 2008; 1521-8.

[3] Ely WE, Stump TE, Hudspeth AS, et al. Thoracic complications of the dental surgical procedures: hazards of the dental drill. Am J Med 1983; 95: 456-65.

[4] Estrera AS, Landay MJ, Grisham JM, et al. Descending necrotizing mediastinitis. Surg Gynecol Obstet 1983; 157: 545-52.

[5] Pinto A, Scaglione M, Scuderi MG, et al. Infections of the neck leading to descending necrotizing mediastinitis: Role of multidetector row computed tomography. Eur J Radiol 2008; 65: 38994.

[6] Scaglione M, Pinto A, Romano S, et al. Determinig optimum management of descending necrotizing mediastinitis with $\mathrm{CT}$; experience with 32 cases. Emergency Radiol 2005; 11: 275-80.

[7] Marty-Ané C-H, Berthet J-P, Alric P, et al. Management of descending necrotizing mediastinitis: An aggressive treatment for an aggressive disease. Ann Thorac Surg 1999; 68: 212-7. 
[8] Corsten MJ, Shamji FM, Odell PF, et al. Optimal treatment of descending necrotizing mediastinitis. Thorax 1997; 52: 702-8.

[9] Papalia E, Rena O, Oliaro A, et al. Descending necrotizing mediastinitis: surgical management. Eur J Cardiothorac Surg 2001; 20: 739-42.

[10] Freeman RK, Vallieres E, Verrier ED, et al. Desending necrotizing mediastinitis: an analysis of the effects of serial surgical debridement on patient mortality. J Thorac Cardiovasc Surg 2000; 119: 260-7.

[11] Sancho LMM, Minamoto H, Fernandez A, et al. Descending necrotizing mediastinitis: a retrospective surgical experience. Eur J Cardiothorac Surg 1999; 16: 200-5.

[12] Iwata T, Sekine Y, Shibuya K, et al. Early open thoracotomy and mediastinopleural irrigation for severe descending necrotizing mediastinitis. Eur J Cardiothorac Surg 2005; 28: 384-8.

[13] Hasegawa T, Endo S, Sohara Y. Classification of descending necrotizing mediastinitis. Ann Thorac Surg 2000; 69: 1295-302.

[14] Baumgmartner FJ, Omari BO, Klein SR. Appropriate exposure and drainage for descending necrotizing mediastinitis. Ann Thorac Surg 1997; 64: 883-92.

[15] Brunelli A, Sabbatini A, Fianchini A. Descending necrotizing mediastinitis: cervicotomy or thoracotomy? J Thorac Cardiovasc Surg 1996; 111: 485-6.

[16] Singhal P, Kejriwal N, Lin Z, et al. Optimal surgical management of descending necrotizing mediastinitis: our experience and review of the literature. Heart Lung Circ 2008; 17: 124-8.

[17] Stella F, Petrella F. Transternal, transpericardial approach for acute descending mediastinitis. J Thorac Cardiovasc Surg 2005; 129: 212-4.

[18] Hirai S, Hamanaka Y, Mitsui N, et al. Surgical treatment of virulent descending necrotizing mediastinitis. Ann Thorac Cardiovasc Surg 2004; 10: 34-8.

[19] Roberts JR, Smythe WR, Weber RW, et al. Thoracoscopic management of descending necrotizing mediastinitis. Chest 1997; 112: 850-4.
[20] Min H-K, Choi YS, Shim YM, et al. Descending necrotizing mediastinitis: A minimally invasive approach using video assisted thoracoscopic surgery. Ann Thorac Surg 2004; 77: 306-10.

[21] Ris H-B, Banic A, Furrer M, et al. Descending necrotizing mediastinitis: surgical treatment via Clamshell approach. Ann Thorac Surg 1996; 62: 1650-4.

[22] Ridder GJ, Maier W, Kinzer S, Tesler C, Bocelelizer C, Pfeiffer J. Descending necrotizing mediastinitis contemporary trends in etiology, diagnosis management and outcome. Ann Surg 2010; 251(3): 529-34.

[23] Gorlitzer M, Grabenwoeger M, Meinhart J, et al. Descending necrotizing mediastinitis treated with rapid sternotomy followed by vacuum-assisted therapy. Ann Thorac Surg 2007; 83: 393-6.

[24] Cho JS, Kim YD, IH, et al. Treatment of mediastinitis using videoassisted thoracic surgery. Eur J Cardiothorac Surg 2008; 34: 520-4.

[25] Endo S, Hasegawa T, Sato Y, et al. Is video-assisted thoracoscopic surgery an optimal approach for descending necrotizing mediastinitis? Ann Thorac Surg 2005; 79: 749-56.

[26] Roccia F, Pecorari GC, Oliaro A, et al. Ten years of descending necrotizing mediastinitis: Management of 23 cases. J Ora Maxillofac Surg 2007; 65: 1716-24.

[27] Misthos P, Katsagarakis S, Kakaris S, et al. Descending necrotizing mediastinitis: Analysis of survival and surgical treatment modalities. J Oral Maxillofac Surg 2007; 65: 635-9.

[28] Chen K-C, Chen J-S, Kuo S-W, et al. Descending necrotizing mediastinitis: A 10-year surgical experience in a single institution. J Thorac Cardiovasc Surg 2008; 136: 191-8.

[29] Sandner A, Borgermann J, Kosling S, et al. Descending necrotizing mediastinitis due to deep neck infections. Incidence and management. HNO 2006; 54: 861-7.

[30] Lin CX, Ding X, Ma YK, et al. Infections of the head and neck leading to descending necrotizing mediastinitis: management of 9 cases. Zhonghua Kou Qiang Yi Xue Za Zhi 2009; 44: 619-20.

[31] Uwa N, Terada T, Saeki N, et al. Clinical features of 5 patients with descending necrotizing mediastinitis originating from deep neckinfection. Auris Nasus Larynx 2010; 37(4): 530-4.

(c) Foroulis and Sileli; Licensee Bentham Open.

This is an open access article licensed under the terms of the Creative Commons Attribution Non-Commercial License (http://creativecommons.org/licenses/bync/3.0/), which permits unrestricted, non-commercial use, distribution and reproduction in any medium, provided the work is properly cited. 